\title{
E-LEARNING EQUIPMENT IN LEARNING PROCESSAT VOCATIONAL HIGH SCHOOL
}

\section{Arif Wahyu Wirawan, Wahyudi}

Universitas Sebelas Maret

id.arifwahyu@gmail.com

\section{Article History}

accepted 30/09/2018

approved 12/10/2018

published 30/10/2018

\section{Keywords}

e-learning, vocational high

schhol, schoology

\begin{abstract}
The problem in the world of education at this time is the quality and quantity of education in the field of information and communication technology. The quality of education can be seen from the quality of education desired by the community and for the quality of education related to the equitable access to education without any gap. One way to overcome these problems is by optimizing the role of information and communication technology in the learning process by using $e$ learning. E-learning used is using online learning based on Schoology. In this application there are several features that can be used by the teacher in the learning process including uploading material, assignments, discussions and giving test questions using the online quiz system. In the use of ELearning in the learning process can increase students' learning motivation and can create enjoyable learning so that students in participating in learning activities can be active and achieve maximum learning outcomes.
\end{abstract}

Social, Humanities, and Education Studies (SHEs): Conference Series https://jurnal.uns.ac.id/shes

p-ISSN 2620-9284 e-ISSN 2620-9292 


\section{PENDAHULUAN}

Kualitas pendidikan dan kuantitas pendidikan menjadi salah satu permasalahan didalam dunia pendidikan. Selain itu, perkembangan teknologi informasi dan komunikasi juga menjadi beberapa permasalahan dalam dunia pendidikan pada saat ini. Kualitas pendidikan dapat dilihat dari mutu pendidikan yang diinginkan masyarakat dan untuk kualitas pendidikan terkait dengan pemerataan akses pendidikan tanpa adanya kesenjangan. Seiring dengan perkembangan teknologi informasi, teknologi komputer dapat menginspirasi banyak ahli khususnya di bidang pendidikan. Seperti halnya, dengan munculnya lembaga yang menyelenggarakan pendidikan jauh seperti: Distance Education, Dual Mode Education, Virtual Education, dan sebagainya.

Dunia pendidikan di Indonesia selalu mengalami perkembangan yang sangat pesat. Dalam hal ini, perkembangan yang semakin beragam adalah penggunakan metode pembelajaran yang digunakan seorang guru. Penggunaan metode pembelajaran yang digunakan oleh guru memanfaatkan berbagai media untuk meningkatkan kualitas pembelajaran. Menurut Sugiharto (2007) model pembelajaran adalah suatu upaya yang dilakukan dengan sengaja oleh pendidik untuk menyampaikan ilmu pengetahuan, mengorganisasi, dan menciptakan sistem lingkungan dengan berbagai metode sehingga peserta didik dapat melakukan kegiatan belajar secara efektif dan efisien serta dengan hasil optimal.

Kemajuan teknologi infomasi dan komunikasi sudah merubah gaya hidup manusia, baik dalam kegiatan bekerja, maupun dalam proses pembelajaran. Memasuki abad 21 dengan kemajuan teknologi perlu adanya standar acuan untuk mecapai suatu tujuan pembelajaran yang diinginkan. Pembelajaran abad 21 diharapkan guru, peserta didik, mahasiswa maupun dosen dituntut untuk memiliki kemampuan dalam proses pembelajaran terutama di bidang teknologi, informasi dan komunikasi.

Di Indonesia E-learning merupakan suatu teknologi pembelajaran yang relatif baru. Untuk mendorong optimalisasi pemanfaatan E-learningmaka lahirlah kebijakan perihal E-learning pada Rencana Strategis Pendidikan dari Departemen Pendidikan Nasional (Depdiknas) 2009-2014 sebagai bagian peningkatan mutu, relevansi, dan daya saing yang disebutkan sebagai berikut: "Dengan mempertimbangkan pesatnya perkembangan pemanfaatan ICT dalam berbagai sektor kehidupan, pemerintah akan terus mengembangkan pemanfaatan ICT untuk sistem informasi persekolahan dan pembelajaran termasuk pengembangan pembelajaran secara elektronik ( $E$-Learning).

Pendidikan Nasional abad 21 bertujuan untuk mewujudkan citacita bangsa, yaitu masyarakat bangsa Indonesia yang sejahtera dan bahagia, dengan kedudukan yang terhormat dan setara dengan bangsa lain dalam dunia global, melalui pembentukan masyarakat yang terdiri dari sumber daya manusia yang berkualitas, yaitu pribadi yang mandiri, berkemauan dan berkemampuan untuk mewujudkan cita-cita bangsanya (BSNP, 2010). Di tengah ketatnya ketidakpastian dan tantangan yang dihadapi setiap orang inilah, maka dibutuhkan perubahan paradigma dalam sistem pendidikan yang harus dapat menyediakan seperangkat keterampilan abad 21 yang dibutuhkan oleh peserta didik guna menghadapi setiap aspek kehidupan global (Soh, Arsad \& Osman, 2010).

Perkembangan teknologi informasi dan komunikasi mempengaruhi dalam bidang pendidikan. Pada dasarnya pendidikan adalah proses komunikasi dan informasi dari seorang pendidik kepada peserta didik yang berisi terkait dengan informasi pendidikan, yang mempunyai unsur pendidik sebagai sumber informasi, media sebagai penyedia ide, gagasan dan materi pendidikan serta bagi peserta didik itu sendiri. Salah satu permasalahan yang muncul dengan adanya perkembangan teknologi di Sekolah Menengah Kejuruan adalah dengan kurangnya sarana dan prasarana yang tersedia di sekolah. 
Implementasi dari penggunaan E-learning bertujuan untuk memaksimalkan ilmu pengetahuan yang sudah diperoleh dari peserta didik. Didalam penggunaan $E$ learningterdapat beberapa konten dimana kegiatan diskusi seperti dikelas dan beberapa pengnaan kuis juga dapat digunakan. Penggunaan E-learning yang ada di Sekolah Menengah Kejuruan adalah menggunakan aplikasi Schoology. Aplikasi tersebut merupakan salah satu penyedia jasa pembelajaran online secara gratis. Guru dapat menyampaikan materi tambahan atau materi pendukung dengan menggunakan pembelajaran online. Penggunaan aplikasi Shoology dianggap lebih menguntungkan dan mempermudah guru dalam membuka kelas virtual, mendefinisikan materi, upload materi, membuat quiz pre-test maupun mampu menambahkan beberapa fitur dalam menggunakan aplikasi E-learningtersebut. Keunikan dari aplikasi Schoology yaitu dengan adanya peran orang tua dan penggunaan kelas virtual dalam pembelajaran $E$ Learning. Peran orang tua dalam hal ini adalah ketika orang tua ingin melihat hasil pekerjaan peserta didik dan nilai-nilai dari peserta didik dapat diketahui langsung orang tua. Sedangkan bagi peserta didik, kelebihan dari aplikasi Schoology ini adalah penggunaan aplikasi ini dapat digunakan di handphone dengan OS (Open Source) android yang pastinya para peserta didik sudah memiliki alat komunikasi dengan sistem OS tersebut.

E-learning merupakan salah satu bentuk model pembelajaran yang difasilitasi dan didukung pemanfaatan teknologi informasi dan komunikasi. E-learningmempunyai ciri-ciri, antara lain (Clark \& Mayer, 2008) memiliki konten yang relevan dengan tujuan pembelajaran; 2) menggunakan metode instruksional, misalnya penyajian contoh dan latihan untuk meningkatkan pembelajaran; 3) menggunakan elemen-elemen media seperti kata-kata dan gambar-gambar untuk menyampaikan materi pembelajaran; 4) memungkinkan pembelajaran langsung berpusat pada pengajar (synchronous elearning) atau di desain untuk pembelajaran mandiri (asynchronous e-learning); 5) membangun pemahaman dan keterampilan yang terkait dengan tujuan pembelajaran baik secara perseorangan atau meningkatkan kinerja pembelajaran kelompok.

Penelitian ini bertujuan untuk mengetahui bagaimana pemanfaatan E-learning dalam meningkatkan proses pembelajaran di Sekolah Menengah Kejuruan kompetensi administrasi perkantoran.

\section{METODOLOGI PENELITIAN}

Metode penelitian ini menggunakan metode kualitatif. Metode kualitatif digunakan karena dalam penilitian ini melihat pemanfaatan E-learningdi Sekolah Menengah Kejuruan dengan kompetensi bidang Administrasi Perkantoran. Guru dengan bidang Administrasi Perkantoran yang ada di Sekolah Menengah Kejuruan di Surakarta yang dijadikan sebagai sampel penelitian. SMK yang memiliki kompetensi Administrasi Perkantoran yang ada di Surakarta sebanyak 13 SMK. Metode yang digunakan dalam proses pengumpulan data menggunakan metode observasi, wawancara dan studi pustaka.

Metode observasi dilakukan dengan melihat dan mempelajari permasalahan yang ada dilapangan yang berkaitan dengan objek peneli yaitu informasi tentang proses pembelajaran dengan menggunakan E-Learning. Metode wawancara digunakan sebagai pengumpulan data, peneliti terlibat dalam kegiatan wawancara dengan sumber daya manusia sebagi pendukung dalam proses pemanfaatan $E$ learning dalam proses pembelajaran berlangsung. Sedangkan untuk metode studi pustaka dilakukan dengan cara mencari beberapa data pendukung dalam mendefinisikan masalah. Metode studi pustaka digunakan dalam pengumpulan data berupa bentuk jurnal maupun beberapa artikel terkait dengan pemanfaatan E-learning dalam kegiatan pembelajaran. 


\section{HASIL DAN PEMBAHASAN}

Perkembangan teknologi informasi dan komunikasi pada saat ini, kebutuhan akan proses belajar mengajar berbasis teknologi informasi (TI) menjadi salah satu kebutuhan yang sangat penting. Selain perkembangan pendidikan, munculnya pendidikan abad 21 sebagai abad pengetahuan yang ditandai dengan terjadinya teransformasi dari dari masyarakat yang agraris menuju masyarakat industri dan berlanjut ke masyarakat berpengetahuan. (Soh, Arsyad \& Osman,2010). Tujuan dari pendidikan abad 21 yaitu mendorong peserta didik untuk dapat menguasai keterampilan abad 21 yang penting dan berguna bagi mereka agar lebih responsif terhadap perubahan dan pekembangan zaman. Selain itu, pendididikan abad 21 juga mendorong peserta didik agar memiliki pengetahuan dan pemahaman yang mendalam agar dapat menjadi pembelajar sepanjang hayat (life-long learner).

Richard Crawford menyebut proses transformasi abad 21 ini sebagai Era of Human Capital (dalam Sidi, 2003), suatu era di mana ilmu pengetahuan dan teknologi, khususnya teknologi komunikasi berkembang sangat pesat yang berdampak pada persaingan bebas yang begitu ketat dalam segala aspek kehidupan manusia. Undangundang Sistem Pendidikan Nasional No 20 Tahun 2003 Pasal 3 menyebutkan bahwa "tujuan pendidikan nasional adalah berkembangnya potensi peserta didik agar menjadi manusia yang beriman dan bertaqwa kepada Tuhan Yang Maha Esa, berakhlak mulia, sehat berilmu, cakap, kreatif, mandiri, dan menjadi warganegara yang demokratis serta bertanggungjawab". Hal ini berarti bahwa pendidikan nasional di Indonesia diarahkan pada membentuk insan yang memiliki kecakapan yang diperlukan dalam mempertahankan budaya dan jati diri bangsa di tengah-tengah gencarnya gempuran beragam budaya dan peradaban bangsa lain di era globalisasi (BNSP, 2010).

Pemanfaatan model pembelajaran yang menggunakan E-learning menekankan pada sumber daya pembelajaran (resource based learning), atau yang sering dikenal dengan nama learner-centered learning. Penelitian ini diawali dengan kegiatan observasi awal yang berkaitan dengan metode pembelajaran yang digunakan pada SMK di Surakarta. Berdasarkan hasil observasi dan wawancara yang dilakukan dilapangan, bahwa penggunaan model pembelajaran E-learning yang ada di Sekolah Menengah Kejuruan di Surakarta sudah dilakukan dibeberapa SMK dan salah satunya SMK dengan bidang Kompetensi Administrasi Perkantoran. Penggunaan pembelajaran E-learning di lingkungan SMK beberapa menggunakan aplikasi Schoology dan ada beberapa sekolahan yang menggunakan aplikasi E-learning lainnya seperti Edmodo maupun Google Classroom. Dengan model pembelajaran ini, peserta didik mampu mendapatkan bahan ajar melalui perangkat handphone maupun dengan menggunakan komputer dan laptop yang mereka miliki.

Pembelajaran dengan menggunakan E-learning merupakan pembelajaran yang memanfaatkan teknologi internet untuk meningkatkan keaktifan dilingkungan belajar dengan konten yang kaya akan dengan cakupan yang luas. E-learning dapat dimanfaatkan sebagai media pembelajaran untuk mengirimkan serangkaian solusi yang dapat meningkatkan pengetahuan dan keterampilan. E-learning mempunyai ciriciri, antara lain (Clark \& Mayer 2008) memiliki konten yang relevan dengan tujuan pembelajaran; 2) menggunakan metode instruksional, misalnya penyajian contoh dan latihan untuk meningkatkan pembelajaran; 3) menggunakan elemen-elemen media seperti kata-kata dan gambar-gambar untuk menyampaikan materi pembelajaran; 4) memungkinkan pembelajaran langsung berpusat pada pengajar (synchronous elearning) atau di desain untuk pembelajaran mandiri (asynchronous e-learning); 5) membangun pemahaman dan keterampilan yang terkait dengan tujuan pembelajaran baik secara perseorangan atau meningkatkan kinerja pembelajaran kelompok.

Sedangkan menurut Rusman dkk (2011) E-learning memiliki karakteristik, antara lain (a) interactivity (interaktivitas); (b) independency (kemandirian); (c) accessibility 
(aksesibilitas); (d) enrichment (pengayaan). E-learning dapat didefinisikan sebagai sebuah bentuk teknologi informasi yang diterapkan di bidang pendidikan dalam bentuk dunia maya. Istilah E-learning lebih tepat ditujukan sebagai usaha untuk membuat sebuah transformasi proses pembelajaran yang ada di sekolah atau perguruan tinggi ke dalam bentuk digital yang dijembatani teknologi internet (Munir, 2009).

Pemanfaatan E-learning dalam proses pembelajaran sudah dilakukan guru dilingkungan sekolahan. Dalam proses pembelajaran E-learning, seorang guru juga dapat membuat suatu kelas (course) dalam aplikasi E-learning. Selain membuat kelas, guru juga dapat membuat sebuah forum diskusi untuk mendiskusi sebuah pokok bahasan yang akan disampaikan dan dibahas bersama dengan peserta didik. Berdasarkan hasil penelitian, kegiatan belajar mengajar dengan menggunakan $E$ learning dapat meningkatkan minat dan pemahaman materi terhadap peserta didik. Berikut beberapa tampilan E-learning berbasis Schoology sebagai berikut:

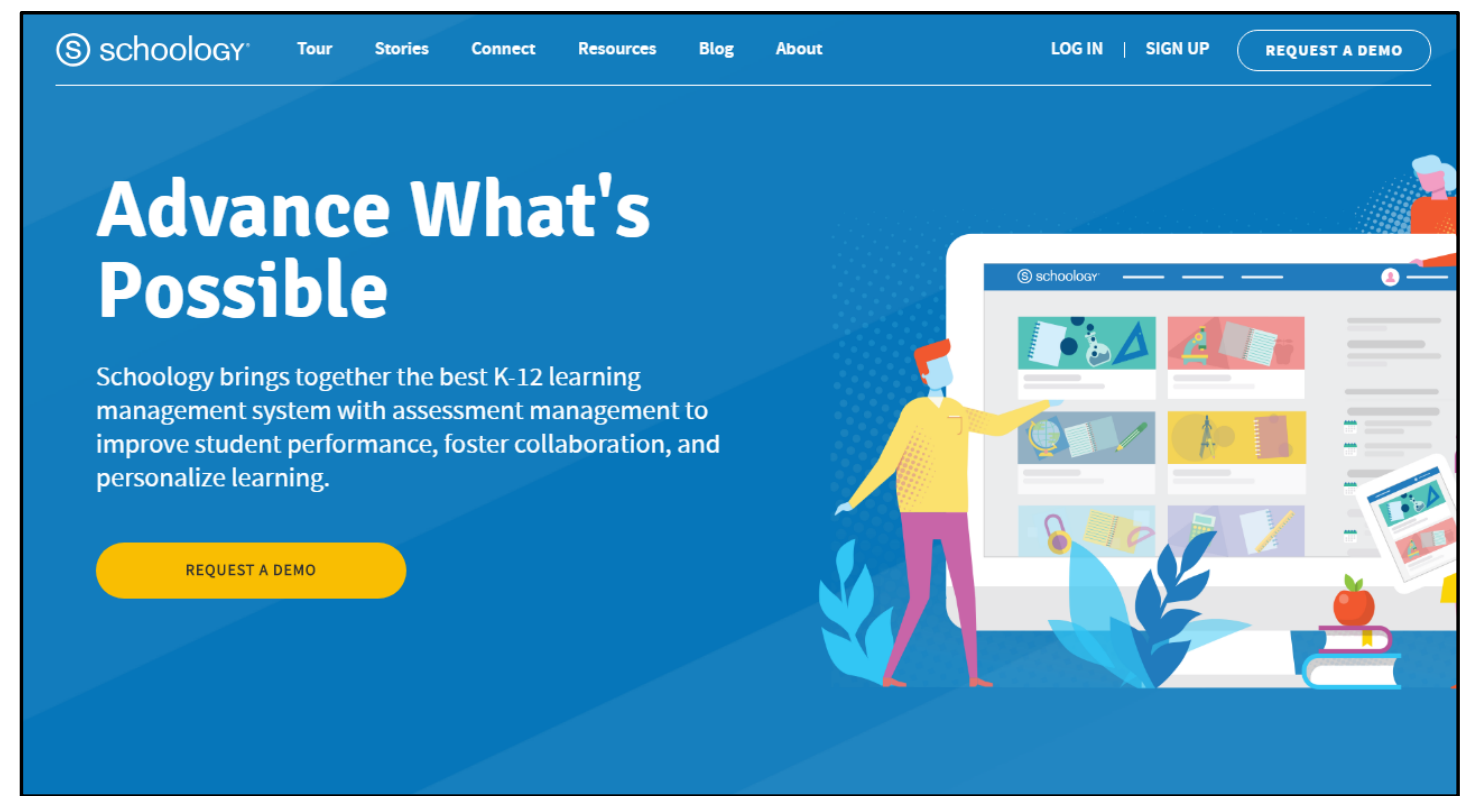

Gambar 1. Tampilan Halaman E-learning (Schoology)

Pemanfaatan E-learning dalam proses pembelajaran juga untuk meningkatkan kualitas pembelajaran yang selama ini beberapa guru hanya menggunakan metode ceramah. E-learning dapat dijadikan sebagai salah satu media pembelajaran seorang guru dalam meningkatkan profesionalisme guru dalam proses pembelajaran di kelas. Beberapa hal perlu dicermati dalam menyelenggarakan metode E-learning adalah pendidik menggunakan internet dan email untuk berinteraksi dengan peserta didik dan mengukur kemajuan belajarnya, peserta didik mampu mengatur waktu belajar, dan pengaturan efektifitas pemanfaatan internet dalam ruang multimedia. Dengan mencermati perkembangan teknologi informasi dalam dunia pendidikan dan beberapa komponen penting yang perlu disiapkan dalam mengembangkan program E-learning maka program E-learning bukanlah suatu yang tidak mungkin untuk diwujudkan.

Seok (2008:) menyatakan bahwa "e-learning is a new form of pedagogy for learning in the $21^{\text {st }}$ century. e-Teacher are elearning instructional designer, facilitator of interaction, and subject matter experts". Penerapan e-learning untuk pembelajaran online pada masa sekarang ini sangatlah mudah dengan memanfaatkan modul Learning Management System yang mudah untuk diinstalasi dan dikelola seperti Moodle.

Dari hasil penelitian tersebut juga sejalan dengan penelitian yang dilakukan oleh Hammed (2008) bahwa penggunaan teknologi informasi sangatlah berguna dalam 
mendukung kegiatan pembelajaran tatap muka dimana hal ini memungkinkan peserta didik memiliki kendali lebih terhadap waktu dan tempat berinteraksi dengan materi pembelajaran. Metode E-learning dimanfaatkan peserta didik dalam kegiatan diskusi terkait materi yang masih belum mereka pahami.

Pembelajaran yang efektif dapat dikatakan pembelajaran yang memanfaatkan teknologi informasi dan komunikasi secara optimal dalam proses pembelajarannya sebagai alat bantu. Salah satu pemanfaatan teknologi informasi dan komunikasi dalam pembelajaran adalah dengan memanfaatkan E-learning.

\section{SIMPULAN}

Pemanfaatan E-learning pada SMK di Surakarta sudah dilakukan dibeberapa sekolah yang memiliki sarana dan prasarana yang memadai. Keberhasilan pemanfaatan E-learning dilihat dari interaksi antara pendidik (guru) dan peserta didik. Dengan adanya penggunaan E-learning peserta didik dan guru dapat melakukan proses pembelajaran di luar sekolah. Dari hasil observasi penggunaan E-learning di Sekolah, penggunaan E-learning menggunakan aplikasi Schoology. Dengan menggunakan aplikasi Schoology guru dan siswa dapat melakukan diskusi menggunakan handphone yang memakai aplikasi android. Didalam aplikasi Schoology juga terdapat beberapa fitur yang dapat digunakan antara lain upload penugasan, sistem tes dengan menggunakan kuis atau beberapa fitur lainnya. Pemanfaatan $E$ learning dapat membawa susasana baru dlam proses pengembangan pembelajaran. Peserta didik dapat saling berbagi informasi dan dapat mengakses materi yang disampaikan oleh guru.

\section{DAFTAR PUSTAKA}

BSNP. (2010). ParadigmaPendidikan Nasional Abad XXI. [Online]. Tersedia:http://www.bsnp-indonesia.org/id/wpcontent/uploads/2012/04/LaporanBSNP-2010.pdf diakses pada tanggal 28 September 2018 Pukul 15.45 WIB

Clark, R.C. \& Mayer, R.E. (2008). E-learning and the science of instruction: proven guidelines for consumers and designers of multimedia learning, second edition. San Francisco: John Wiley \& Sons, Inc.

Hameed, S., Badii, A. \& Cullen, A.J. (2008). Effective E-Learning Integration with Traditional Learning in a Blended Learning Environment.European and Mediterranean Conference on Information System. May 25-26.

Munir. (2009). Pembelajaran jarak jauh berbasis teknologi informasi dan komunikasi. Bandung: Alfabeta.

Rusman, dkk. (2011). Pembelajaran berbasis teknologi informasi dan komunikasi, mengembangkan profesionalitas guru. Jakarta: PT. Raja Grafindo.

Seok, Soonhwa. (2008). The aspect of elearning. International Journal on ELearning, Proquest, 7(4), 725-741.

Sidi. I. D, \& Setiadi. B. N. (2013). Manusia Indonesia abad 21 yang berkualitas tinggi di tinjau dari sudut psikologi. http://himpsi.or.id/publikasi/

Soh, T., Arsad, N., \& Osman, K. (2010). Therelationship of 21st century skills on students' attitude and perception towards physics. Procedia Social and Behavioral Sciences, 7(C), 546-554.

Sugihartono, dkk. (2007). Psikologi Pendidikan. Yogyakarta: UNY Press. 